\title{
UMA INTERROGAÇÃO SOBRE O ENSINO DAS LITERATURAS EM PORTUGUÊS: ENTRE O “CÂNONE LUSÓFONO" E A “EMOÇÃO ESTÉTICO-PATRIÓTICA"
}

\section{A QUESTION ON THE TEACHING OF PORTUGUESE- SPEAKING LITERATURES: BETUEEN THE "LUSOPHONE CANON" AND "AESTHETIC-PATRIOTIC EMOTION"}

\author{
INOCÊNCIA MATA*
}

\begin{abstract}
RESUMO: Para muitos "empresários da memória" dos países de língua portuguesa é politicamente correto declarar que a língua comum funciona no "nosso caso", mais do que em outros casos em que a língua europeia é idioma oficial, como um elo sólido fundamentado numa "história original". Os países de língua portuguesa, quando "chegaram" à arena internacional, encontraram blocos de solidariedade, com base nos mais diversos elementos, já constituídos num mundo globalizado e superdiverso em que, paradoxalmente, a reivindicação da diferença é uma das marcas mais impositivas. Levanta-se a seguinte questão: no estudo da literatura, como "resolver a questão" da nacionalidade dos escritores que escrevem em português? O que ensinar: literaturas em português ou "literatura nacional", entendida como "emoción estético-patriótica" (José-Carlos Mainer)?
\end{abstract}

PALAVRAS-CHAVE: literaturas em português, sistema nacional, "cânone lusófono", cânone escolar, pedagogia intercultural.

ABSTRACT: For many "memory entrepreneurs" in Portuguese-speaking countries, it is politically correct to declare that the common language works in our case, more so than in other cases where the European language is an official language, as a solid link based on a "history original". The Portuguese-speaking countries, when they "arrived" in the international arena, found blocks of solidarity, based on the most diverse elements, already constituted in a globalized and super-diverse world in which, paradoxically, the claim of difference is one of the most imposing brands. The following question arises: in the study of literature, how to "solve the question" of the nationality of writers who write in Portuguese? What to teach: literatures in Portuguese or "national literature", understood as "aesthetic-patriotic emotion" (José-Carlos Mainer)?

KEYWORDS: literatures in portuguese, national system, "lusophone canon", school canon, intercultural pedagogy.

\footnotetext{
* Professora da Faculdade de Letras da Universidade de Lisboa na área de Literaturas, Artes e Culturas, Portugal.
} 
em sido recorrente, sobretudo desde a constituição da CPLP, em 1996, e, particularmente do Instituto Internacional da Língua Portuguesa (IILP), em 2002, ${ }^{1}$ a preocupação de alguns decisores políticos e "empresários da memória" quanto à aproximação dos conteúdos curriculares em, especificamente, História e Português. Julgo que é consensual considerar a explosiva temeridade do primeiro caso - os currículos, programas e manuais de História - e já o tenho dito publicamente, citando, por exemplo, duas primeiras grandes dificuldades (o que, porventura, causará incomodidade aos proponentes): como referir o período precedente à implantação do sistema colonial em África - guerras de resistência ou guerras de pacificação? Ou, mais recentemente, como designar o período de conflito que opôs o regime colonial às vanguardas nacionalistas africanas - guerra do Ultramar/guerra colonial ou guerra de libertação? No entanto, já o segundo caso, referente ao ensino da Literatura, embora se possa discordar quanto a estratégias, critérios, métodos e metodologias para a implementação da constituição de um catálogo de textos representativos, em antologias ou manuais, que possibilitem essa aproximação e um conhecimento literário mútuo, parece-me exequível, se pensarmos nesse catálogo como um princípio, como uma "base curricular comum" no âmbito da Educação literária nos níveis do ensino obrigatório.

Em Dezembro de 2015, Vítor Manuel Aguiar e Silva abriu o congresso internacional A Língua Portuguesa: uma Língua de Futuro (Coimbra, 2-4 de Dezembro) com uma conferência intitulada "Em busca de um cânone literário para a língua portuguesa", que foi resumida como "[uma] proposta concreta para aproximar as literaturas de língua portuguesa" (QUEIRÓS, 2015). Aguiar e Silva junta-se a outros académicos portugueses que têm vindo a reflectir sobre essa possibilidade, de entre os quais se citam Carlos Reis, Fernando Cristóvão, Annabela Rita e José Carlos Venâncio que, no entanto, diferem em perspectivas: por exemplo, enquanto Annabela Rita fala em "jogo de espelhos" que tende à rarefação do nacional, não obstante a referência a uma "pulsação pluricênctrica", Fernando Cristóvão fala na necessidade de se considerarem categorias "não só estéticas mas histórico-culturais e sociais próprias e diversas das tradicionais" (CRISTÓ-

\footnotetext{
${ }^{1}$ A proposta da criação de um Instituto Internacional da Língua Portuguesa foi feita em 1989, em São Luís do Maranhão, mas foi apenas em 2020, na VI Reunião Ordinária do Conselho de Ministros da CPLP, em São Tomé, que foi formalizada a criação do IILP.
} 
VÃO, 2015, p. 250) - que se subentende serem de diferentes áreas geoculturais. Não obstante aquilo que parece ser alguma divergência na criteriologia, julgo que é consensual a ideia de que as obras constantes desse catálogo teriam de consagrar valores históricos e socioculturais e não apenas estéticos, como tem sido o entendimento de cânone, na perspectiva bloomiana.

Não é despicienda a questão da aproximação dessas literaturas, atrás referida a propósito de afirmação de Aguiar e Silva, questão interessante até para suscitar uma discussão que me pareceria legítima: é que essas propostas de aproximações costumam acabar por serem feitas a partir de padronizações e "directórios" estéticos que supostamente visam a universalidade, categoria normalmente veiculadora de visões do estético hegemónicas que desconsideram outros matizes literários, configurações e sensibilidades estéticas não europeias ou ocidentais. ${ }^{2}$ No entanto, parece-me também importante reflectir sobre as possibilidades da construção ${ }^{3}$ de um cânone literário (escolar) que mostre a diversidade da língua portuguesa e de suas literaturas, mesmo tendo em conta as oscilações das sensibilidades epocais e dos paradigmas culturais e estéticos (RITA, 2015, p. 134). Sim, porque é, neste contexto de partilha de patrimónios literários, sobre um "cânone escolar" que importa reflectir e é sobre isso que falou Vítor Manuel Aguiar e Silva, fundamentando-se na dimensão transnacional e transcultural da língua portuguesa. A sua proposta não parece apontar, no

\footnotetext{
2 Sobre esta questão da "universalidade" já tenho escrito: "O universal e o local nas literaturas africanas: uma dicotomia sem suporte". Revista ECOS: Linguística, Letras e Artes - Centro de Pesquisa em Literatura (CEPLIT), Grupo de Pesquisa em Estudos da Arte e da Literatura Comparada e do Programa de Pós-Graduação Stricto Sensu em Estudos Literários (PPGEL), da Universidade do Estado de Mato Grosso (UNEMAT), Edição no 01, n. 2 - janeiro 2004 (2006), "'Even Crusoe needs a Friday'”: os limites dos sentidos da dicotomia 'universal/local' nas literaturas africanas". Gragoatá - revista dos Programas de Pós-graduação em Letras da UFFv. 10, n. 19 (2005); "Estudos pós-coloniais: desconstruindo genealogias eurocêntricas". Civitas - Programa de Pós-Graduação em Ciências Sociais/Faculdade de Filosofia e Ciências Humanas da Pontifícia Universidade Católica do Rio Grande do Sul - PUCRS, v. 14 n. 1 p. 1-194 jan.-abr. 2014.

${ }^{3}$ Vários têm sido os termos usados para designar esse processo: Fernando Cristóvão fala em formação, definição, elaboração; Carlos Reis de configuração, formação e conformação; Annabela Rita de (re)composição, enquanto José Carlos Venâncio refere a existência de uma cânone lusófono que parece decorrente do processo histórico das ex-colónias. À excepção do último caso, em que é evidente a fundamentação luso-tropicalista freyriana, ainda não apercebi dos efeitos pragmáticos dessas opções terminológicas. A minha opção - construção, constituição - tem a ver com facto de esse processo ser o de uma invenção que se baseia em critérios externos à literatura, embora não à instituição literária.
} 
entanto, para a "desnacionalização do cânone literário escolar" (SIMÕES, 2015), como equivocadamente se poderá ter pensado, uma vez que na sua proposta o autor considera que, apesar de "um acordo, um consenso" - o que afasta a ideia de uma "norma [literária] exclusiva e excludente", como sói ser -, os autores a serem incluídos seriam da escolha de cada ideologia nacional, isto é, a selecção dos textos e autores seria feita por entidades indicadas por cada um dos países, e estas escolhas conjugadas dariam depois lugar a uma antologia (AGUIAR E SILVA apud QUEIRÓS, 2015). Isso significa que a inclusão de um autor ou um texto numa tal antologia seria não apenas um atestado da sua importância no "seu" sistema literário e da sua qualidade (do autor ou do texto), mas também o facto de determinado texto ou autor estar incluído nessa antologia considerada autoridade seria uma atribuição tácita de um estatuto canónico (ainda que esse estatuto não seja eterno, definitivo, como os manuais da história da literatura nos tem vindo a ensinar). ${ }^{4}$ Não por acaso o jornalista Luís Miguel Queirós, que tem vindo a perseguir, jornalisticamente, esta questão numa ligeira sondagem sobre a questão, deu o seguinte título ao seu artigo: "Cânone literário lusófono: uma ideia que provoca resistências" (QUEIRÓs, 2016).

Resistência, palavra que eu substituiria por questionamentos ou interrogações, e que não tem a ver com a "manutenção de preconceitos anticoloniais", como afirma Fernando Cristóvão (2015, p. 248), que também refere dois preconceitos de "alguma historiografia literária demasiado patriótica": tanto a invenção de "míticas origens para esconder as origens coloniais" quanto a adopção de uma visão xenófoba decorrente de "uma crença arbitrária pós-colonial que valoriza como autêntico e nacional só quanto foi elaborado depois da independência do país" (CRISTÓVÃO, 2015, p. 250-1) - o que, obviamente, não procede, uma vez que aquilo que na historiografia literária africana (das literaturas africanas em português, pois é delas que se fala) é considerado constitutivo da "tradição literária" é precisamente a estética nativista e nacionalista, desde a 2.a meta-

\footnotetext{
${ }^{4}$ Um desses "manuais" é a História da Literatura Portuguesa (1955), de Óscar Lopes e António José Saraiva, que ao longo das suas quase duas dezenas de edições tem vindo alterado o estatuto de alguns (ainda que poucos) autores e incluído alguns outros. Outro exemplo pode vir do livro de Differencing the Canon : feminist desire and the writing of art's histories (1999), de Griselda Pollock, em que a autora questiona o cânone da arte, que se pauta por uma ausência de artistas femininas, através de "abordagem feminista". Ou ainda, o cânone literário brasileiro que tem vindo a ser interrogado por causa da ausência de escritores afro-descendentes.
} 
de do século XIX aos anos 70 do século XX, portanto, anterior à independência nacional. Essa resistência, a existir (nos moldes referidos por Luís Miguel Queirós), funciona, pois, como questionamentos e interrogações que se levantam em relação aos critérios de selecção, catalogação e antologização, tratando-se de países com diferentes percursos históricos (confrontacionais não raro), culturas e ideologias culturais diversas, inconciliáveis em algumas categorias, mesmo em tempo de valorização da intensa multiculturalidade que caracteriza este mundo globalizado e de políticas solidariedades (como são os blocos de países por percursos históricos e partilhas linguísticas). E, neste contexto, faz sentido reiterar a seguinte interrogação, parafraseando Carlos Reis: ${ }^{5}$ faz sentido falar de um cânone literário aplicável a universos culturais de conformação pós-colonial?

Na verdade, do que se fala aqui é de um corpus formado por textos que representam determinada "literatura como sistema nacional" e que vão ser legitimados ao nível do discurso pedagógico como "referentes normativos (curriculares e didáticos)" (REIS, 2017, p. 29). Ou, como o define António Branco, "o conjunto de textos que os programas oficiais consideram de estudo obrigatório, por ser considerado ilustrativo da excelência e da variedade de um património nacional merecedor de conservação e perpetuação" (BRANCO, 1999).

Parece ser, para aqueles "empresários da memória" dos países de língua portuguesa, politicamente correto declarar que a língua comum funciona, no "nosso caso" mais do que em outros casos em que a língua europeia é idioma oficial, como um elo sólido fundamentado numa "história original". Creio que há uma razão para tal pressuposição, ou desiderato, ainda que ela possa ser mais ideológica do que histórico-cultural. Os países de língua portuguesa, quando "chegaram" à arena internacional, encontraram blocos de solidariedade, com base nos mais diversos elementos, já constituídos num mundo globalizado e superdiverso que não escapa, no entanto a jogos de hegemonia. Essa geografia de poder é facilmente cartografável, por exemplo, na lista de O cânone ocidental (1994), de Harold Bloom, cujo subtítulo é, significamente, "Os grandes livros e os escritores

\footnotetext{
${ }^{5}$ A pergunta de Carlos Reis é: "Faz sentido falar de cânones literários em universos culturais de conformação pós-colonial?” (REIS, 2017, p. 29). A interrogação fez-se singular (pois é essa a proposta a ser discutida).

${ }^{6} \mathrm{Na}$ esteira de Antonio Candido (Formação da literatura brasileira, 1945, em reedições sempre actualizadas), ideia que Fernando Cristóvão retoma no seu ensaio "A literatura como sistema nacional" (1981).
} 
essenciais de todos os tempos", em que predomina a geocultura literária anglo-saxónica, construída com base em critérios exclusivamente literários sem ter em conta valores socioculturais e históricos, que são igualmente duas dimensões importantes da literatura coexistentes com a estética que, na verdade, é fundadora do literário; do mesmo modo, essa geografia do poder manifesta-se em muita crítica literária quando o diálogo intertextual de um escritor africano com um determinado autor da literatura europeia, ocidental, faz desse escritor "universal", não acontecendo o mesmo se esse diálogo é com uma obra africana. Porém, mundo globalizado que é, paradoxalmente, caracterizado por uma intensa reivindicação da diferença. Temos que nos defender e para tal temos de nos unir - este parece, pois, ser o lema que corporiza essa convicção.

Uma das categorias deste desiderativo pressuposto elo é a literatura. Aqui, a ideologia (e, até, a emoção, no sentido de afectividade) prevalece sobre qualquer epistemologia quando se fala em "cânone" e "cânone lusófono". Não pretendendo entrar na longa discussão sobre o termo lusofonia, é preciso ter em conta que "a configuração de um cânone não é coincidente com a formação e com a consolidação sociocultural de uma literatura nacional, sendo-lhe inevitavelmente subsequente" (REIS, 2017, p. 32). Carlos Reis comentava a perspectiva de Antonio Candido no seu emblemático Formação da literatura brasileira; porém, é possível aplicar esta consideração ao "caso africano", e neste contexto talvez seja por causa dessa particularidade, própria de literaturas jovens (que não tem a ver com a ideia da condição emergente, justamente criticada por Fátima Mendonça), ${ }^{7}$ que faz sentido que alguns escritores africanos possam reivindicar o estatuto de "escritores de língua portuguesa", aparecendo no acervo que lhes convenha, circunstancialmente, como é o caso de José Eduardo Agualusa, que, em 2007, se definiu como afro-luso-brasileiro por não simpatizar "com a ideia de nações nem com fronteiras", 8 ou possam ser inseridos no acervo da literatura portuguesa, numa omissão do sistema nacional de que fazem parte - tal é o caso de Paula Tavares que aparece, entre 2000 escritoras, no Dicionário de escritoras portuguesas: das origens à atualidade, de Conceição Flores (2009), Constança Lima Duarte e Zenóbia Collares Moreira. Esse facto, não obstante o claro corte nacional que o título ostenta (pois por "escritoras portuguesas" entende-se

\footnotetext{
${ }^{7}$ Ver Mendonça, 2008, p. 19-34.

${ }^{8}$ Ver Silva, 2017.
} 
aquelas que integram o património literário de Portugal), pode ser lido como um gesto de inclusão e constitutivo de uma "literatura lusófona" e, portanto, de rarefação da nacionalidade, e parece sugerir a existência de um conjunto sistemático de pluricêntricas relações de dialécticas gramáticas em língua portuguesa. Porque, como nos lembra Maria de Lurdes Dionísio ([2000] 2010), "[a] função da literatura na escola sempre esteve muito além do exemplo linguístico, ela tem uma função de preservação da cultura nacional".

Por outro lado, não é raro assistir-se à exclusão, pela crítica (sobretudo a jornalística) de determinados escritores desse catálogo, ainda que informal, mas que se pode considerar precursor de um "cânone lusófono", sobretudo quando a escritura contextual e histórica dessoutros escritores é mais incisiva na reivindicação nacional, menos "pastoral" (ELLA SHOHAT, 1992). A questão que se levanta é: no estudo da literatura - por exemplo, a nível secundário, no programa da disciplina de Português (ou, até, uma unidade curricular como Literaturas Pós-coloniais Comparadas, leccionada na Faculdade de Letras da Universidade de Lisboa) "solapar" a nacionalidade dos escritores que escrevem em português para os integrar num "catálogo transnacional" pode passar pela abertura a perspectivas poliédricas de comparação que possibilitem a construção de uma visão prismática das literaturas em português e permitam conduzir a uma percepção de diferentes gramáticas culturais da língua portuguesa, e seus representantes e andamentos, para dar conta da diversidade literária de expressões culturais e societais em português (de que se tem, parece por vezes, uma visão muito preceptística e não "realista"). É o que é sugerido no documento Programa e Metas Curriculares de Português: Ensino Secundário (do Ministério da Educação e Ciência de Portugal) no que diz respeito à "Educação Literária":(...) no domínio da Educação Literária prevalece o princípio da representatividade, invariavelmente mobilizador de outros critérios centrais em qualquer dos géneros literários previstos. São eles o valor históricocultural e o valor patrimonial associados ao estudo do Português, nas suas dimensões diacrónica e sincrónica. (BUESCU et al., 2014, p. 5)

Neste contexto, vale a pena recordar uma das interrogações com que comecei esta reflexão: quais as vantagens de ensinar literaturas em português (ou 
"lusófonas") 9 na perspectiva de "literatura nacional" entendida como "emoción estético-patriótica", na expressão do crítico espanhol José-Carlos Mainer, no seu brevíssimo quanto instigante apontamento jornalístico sobre "Literatura nacional" (2011): isto é, autores consoante a sua origem geocultural, convocando, para o efeito, uma pedagogia intercultural que dê conta da diversidade literária de expressões culturais em português? E que vantagens para o seu contrário, isto é, ensinar literaturas rasurando as suas geografias culturais?

Há, assim, quem defenda a exequibilidade da constituição de um cânone lusófono - isto é, um conjunto de grandes escritores dos diferentes países de língua portuguesa que a trabalharam, a afeiçoaram e a reinventaram (AGUIAR E SILVA, 2015), que funcione "como instrumento de formação identitária da "comunidade" que se julga corporizada nessa designação, para o qual se dissolveriam as identidades históricas, étnicas, ideológicas de cada segmento dessa comunidade. Exequível? Sim. Desejável por essas comunidades imaginadas? Não sei. O que sei é compreendo uma eventual necessidade de discussão pelas razões atrás aduzidas a proposta de - voltando à questão inicial - uma aproximação (ainda que esta seja, neste âmbito, uma noção muito generosa, embora nebulosa) dessas literaturas tendo em conta os seus contextos geoculturais e históricos: a não ser que se pense em múltiplas outras aproximações - literatura moçambicana/literatura zimbabueana; literatura brasileira/chilena; literatura guineense/literatura senegalesa... Mas estamos - poderão argumentar - a falar de um "cânone escolar" e pode ser que estas questões não procedam: sim, mas não há literatura estrangeira no Plano Nacional de Leitura? Regressando ao Programa e Metas Curriculares de Português, esta questão parece ser contemplada nas considerações sobre uma Educação Literária, na necessidade de se sublinhar "o pressuposto do diálogo entre culturas, objetivo primordial do Projeto de Leitura, que acrescenta às aprendizagens do domínio da Educação Literária o contacto direto com outros textos em português (de língua portuguesa e em tradução portuguesa)" (BUESCU et al., 2014, p. 5).

\footnotetext{
${ }^{9}$ Como afirmo no resumo enviado, esta é uma designação muito disseminada já, na esteira da "literatura francófona", expressão que, embora recusada por muitos intelectuais africanos, continua a fazer o seu percurso - o que não significa que "os povos [...] hoje se consideram lusófonos", como afirma Annabela Rita no seu artigo intitulado "Lusofonia e literatura: Haverá cânone(s) lusófono(s)?" (2015, p. 141).
} 
Em todo o caso, um tal projecto - a constituição de um cânone lusófono teria como propósito não congelar a norma, nem a linguística nem a literária, mas discipliná-las para as fazer dialogar, na medida do desejável, para que se crie uma norma policêntrica que vise uma solidariedade entre a língua que se fala e se escreve nesses diversos espaços, e não, como também sói ouvir-se, neutralizar uma qualquer deriva lexical, morfo-sintáctica e pragmática. É esse diálogo a vantagem por excelência, para que a indignação por não se estudar literatura portuguesa no Brasil, como se deveria (polémica que ciclicamente irrompe no Brasil e tem repercussão em Portugal), seja a mesma ao verificar-se que nos programas curriculares portugueses as literaturas brasileira e africanas são "opcionais" (que no caso significa que não são estudadas), isto é, estão lá referidas, é verdade, mas o professor pode optar por ignorar essas "sugestões", sem que haja quaisquer consequências em termos de avaliação... E sem que essa ausência "incomode" a consciência dos responsáveis pela Educação, numa sociedade multicultural em que importa fomentar o diálogo entre culturas, para promover a competência intercultural como corolária da competência literária e o aluno, adolescente e jovem, num ser capaz de estabelecer pontes de diálogo com o Outro - que no discurso oficial é entendido como fazendo parte de uma mesma comunidade...

Muitas questões se levantam quando se pretende discutir os critérios para a elaboração de um cânone lusófono escolar, isto é, uma lista ou um catálogo de autores e textos com "carácter de exemplaridade e, simultaneamente, [que] consagram também valores socioculturais, para além dos estéticos" (CRISTÓVÃO, 2015, p. 247) e que devem constar dos programas escolares. E valores históricos, acrescento. Questões que, já o disse, têm a ver com a ideologia cultural: de quem seria a autoria da selecção? Que textos representam as comunidades? O que se pretende que os textos veiculem? Qual o lugar da academia nesse processo? Qual o lugar das editoras? O que e como pretende o Estado - afinal o regulador dos currículos, programas e manuais de ensino - que os alunos aprendam da história e da cultura do país? Que línguas incluir, para além do português? Em que medida a circunstância dos textos é categoria negligenciável? Por que é menos grave os alunos portugueses não estudarem literatura brasileira que alunos brasileiros não estudarem literatura portuguesa? Por que é "natural" que alunos africanos conheçam Camões, Pessoa e Sophia (ou outros patrimónios literários traduzidos para o português como Robinson Crusoe, 
O principezinho/ O pequeno príncipe ou Fábulas de Esopo), mas se considera que não constitui lacuna na formação se alunos portugueses não conhecerem Craveirinha, Luandino ou Tenreiro (para não falar de outros patrimónios africanos que, traduzidos para o português, deveriam constar dos planos de leitura em qualquer parte do mundo - e penso no caso de Things Fall Apart/ Quando tudo se desmorona/ O mundo se despedaça, de Chinua Achebe)?

$\mathrm{Na}$ verdade, esta reflexão veicula mais interrogações que propostas. A defesa da elaboração de um "cânone lusófono" é produtiva porque obriga a que se discutam assuntos menos pastorais neste contexto pós-colonial. Mas talvez mais produtivo se torne falar em "cânones lusófonos" (no plural) - cânone que, se parece estabilizado na literatura portuguesa, está em mutação na literatura brasileira com o combate pela visibilização, contra o silenciamento, da literatura de autoria afro-descendente (a chamada literatura afro-brasileira, designação porventura inadequada embora compreensível em determinado contexto), enquanto nas literaturas africanas é uma questão em (por vezes tensa) discussão, como o demonstram a prevalência de escritores luso-descendentes em Portugal e no Brasil (mas não nos países desses escritores, o que só por si é sintomático de algum fenómeno) e uma proposta que em Angola gerou muita polémica, a enclopédica Biblioteca de literatura angolana (2005), de Mena Abrantes, em 12 volumes, publicada pelas Edições Maianga, com o apoio da Odebrecht, em que apenas um escritor negro, Agostinho Neto, é considerado. Aqui chegados, não procede o discurso de que o que "importa é o estético" (dito por quem politico-correctamente invectiva Harold Bloom, mas com ele partilha, afinal, a ideologia do cânone) pois, como bem lembra Carlos Reis (e outros antes e depois dele),

Quando chegamos a África [...], o mapa literário exibe uma complexidade enraizada nos ditames da Conferência de Berlim de 1884. Sem prejuízo das diferenças e das exceções, estamos agora em universos pós-coloniais que correspondem a independências recentes, onde permanece viva a conflitualidade política e até étnica [...]. (REIS, 2017, p. 39. Meu destaque)

É essa conflitualidade - a que o jornalista acima citado chamou resistência que importa enfrentar, pois o que é unânime é que à diversidade da língua portuguesa deve corresponder à diversidade de expressões literárias a transmitir aos mais novos, inclusivamente usando a diferença (cultural, mundivivencial das 
personagens, espacial; até diferença de percepção genológica - como é o caso da diferença entre conto e estória), como força dinâmica para abrir as possibilidades de leitura dos textos literários em português. E entendendo literatura como expressão, comunicação, representação, mas também património, este é, também, um dos aspectos da educação para a diferença.

\section{Referências:}

BLOOM, Harold. O cânone ocidental. Lisboa: Editorial Caminho, 2001.

BRANCO, António. Pedagogia do cânone literário escolar: adequação e violência, rejeição e desejo. Revista Literacias: Práticas, Teorias e Ícones, 1999. Disponível em: <http://www.ectep.com/ literacias/canone.html>. Acesso em: 14 maio 2015.

BUESCU, Helena C.; MAIA, Luís C.; SILVA; Maria Graciete; ROCHA Maria Regina. Introdução. In: Programa e Metas Curriculares de Português: Ensino Secundário. Lisboa: Ministério da Educação e Ciência, Janeiro de 2014 (atualizado). Disponível em: <http://www.dge.mec.pt/sites/ default/files/ficheiros/programa metas curriculares portugues secundario.pdf. $>$ Acesso em: 12 out. 2017.

CRISTÓVÃO, Fernando. Sugestões de critérios convergentes prévios para a formação e definição de um cânone lusófono. In: MARTINS, Moisés Lemos (Coord..). Lusofonia e Interculturalidade: promessa e travessia. Vila Nova de Famalicão: Húmus, 2015, p. 245-252.

CRISTÓVÃO, Fernando. A literatura como sistema nacional. Brotéria - Cultura e Informação (Lisboa), vol. 112, n4, p. 363-383, abr.1981.

DIONÍSIO, Maria de Lurdes. Entrevista (2000). In COELHO, Luísa Isabel Carvalho Leitão Gomes. Manual: leitura (s) caleidoscópica (s) e subsídios para o cânone escolar literário. Covilhã: UBI, 2010.

MAINER, José-Carlos. Literatura nacional. El País, Madrid, 28 maio 2011. Disponível em: <http:// elpais.com/diario/2011/05/28/babelia/1306541562 850215.html>. Acesso em: 7 out. 2015.

MENDONÇA, Fátima. Literatura emergentes, identidades e cânone. In CALAFATE, Margarida Ribeiro; MENESES, Maria Paula (Eds.). Moçambique: das palavras escritas. Porto: Edições Afrontamento, 2008, p. 19-34.

QUEIRÓS, Luís Miguel. Cânone literário lusófono: uma ideia que provoca resistências. Público Lisboa, 6 mar. 2016.

QUEIRÓS, Luís Miguel. Um cânone literário que mostre a diversidade da língua portuguesa (Entrevista a Vítor Manuel Aguiar e Silva). Público. Caderno Ípsilon. Lisboa, 2 dez. de 2015.

REIS, Carlos. Diversidade e cânone literário: cinco teses. In FERREIRA, A. M.; MORAIS, C.; BRASETE, M. F.; COIMBRA, R. L. (Eds.). Pelos mares da Língua Portuguesa 3. Aveiro: UA Editora, 2017, p. 29-43. 
RITA, Annabela. Lusofonia e literatura: haverá cânone(s) lusófono(s)?. In MARTINS, M. L. (Coord.). Lusofonia e interculturalidade: promessa e travessia. Vila Nova de Famalicão: Húmus, 2015, p.120-151.

RITA, Annabela. Luz \& sombras do cânone literário. Lisboa: CLEPUL/Esfera do Caos Editores, 2014. SILVA, Helena Teixeira da. José Eduardo Agualusa: "Não sinto necessidade de escrever como de fazer amor". Disponível em: $\leq$ http://inverao.blogs.sapo.pt/12458.html>. Acesso em: 5 out. 2017. SIMÕES, Isabel. Aguiar e Silva propõe a "desnacionalização do cânone literário escolar". Radio Universidade de Coimbra. Disponível em: <http://www.ruc.pt/2015/12/02/vitor-manuel-de-aguiar-e-silva-propoe-a-desnacionalizacao-do-canone-literario-escolar-para-a-lingua-portuguesa/>. Acesso em: 5 out. 2017. 